\title{
Design and Analysis of Higher Efficiency Non isolated DC-DC Converter for Electric Vehicles
}

\author{
K. Keerthi, Y. Bhavya Sree, S. Ravi Teja, M. Sai Krishna Reddy, B. Jyothi
}

\begin{abstract}
The design and analysis of higher efficiency non isolated DC-DC converter for Electric Vehicles is presented. A Battery Charging System (BCS) plays a key role in achieving fast charging and higher efficiency. The BCS integrates acascaded DC-DC converter and a bidirectional PWM converter. In order to achieve more reliability and stiff voltage, aCascaded buckboost converter which is partitioned with the help of a capacitor is integratedand to achieve higher efficiency with less number of switches, a bidirectional PWM converter used There are various PWM techniques, among them hysteresis and sinusoidal pwm technique are used. The output voltage obtained after both the operations (boost and buck) is given to the battery or load. Simulation is done in MATLAB and the results are analyzed with PI controller and without PI controller in this paper.
\end{abstract}

Keywords-Electric Vehicle,BCS,DC-DC converter, cascaded Buck-Boost converter, Bi-directional PWM converter, PI controller, MATLAB/ SIMULINK.

\section{INTRODUCTION}

Global climatic conditions and Fossil Fuel depletion are advancing in the environment. Based on the concerns regarding climatic conditions and environmental pollution issues arises from fossil fuel energy sources, many researches had developed another dimension of vehicles to reduce pollution.Apart from these, we can see that in recent years a large number of advanced techniques came into existence, so in order to minimize these issues. Concerning these issues and advanced techniques from industries, and by using applications of green energy, renewable energy sources an Electric Vehicle (EV) is designed[1-3].Countless studies have undergone to improve the efficiency and Power density of an Electric Vehicle and succeeded in it.

Revised Manuscript Received on December 30, 2019.

* Correspondence Author

K. Keerthi*, B.Tech, Department of Electrical and Electronics Engineering, KoneruLakshmaiah Education Foundation, Vaddeswaram, AP, India.

Y. Bhavya Sree, B.Tech, Department of Electrical and Electronics Engineering, KoneruLakshmaiah Education Foundation, Vaddeswaram, AP, India.

S.Ravi Teja, Asst. Professor, Department of Electrical and Electronics Engineering, KoneruLakshmaiah Education Foundation, Vaddeswaram, AP, India.

M. Sai Krishna Reddy, Asst.Professor, Department of Electrical and Electronics Engineering, KoneruLakshmaiah Education Foundation, Vaddeswaram, AP, India.

B.Jyothi, Professor, Department of Electrical and Electronics Engineering, KoneruLakshmaiah Education Foundation, Vaddeswaram, AP, India.

(C) The Authors. Published by Blue Eyes Intelligence Engineering and Sciences Publication (BEIESP). This is an open access article under the CC BY-NC-ND license (http://creativecommons.org/licenses/by-nc$\underline{n d / 4.0 /)}$

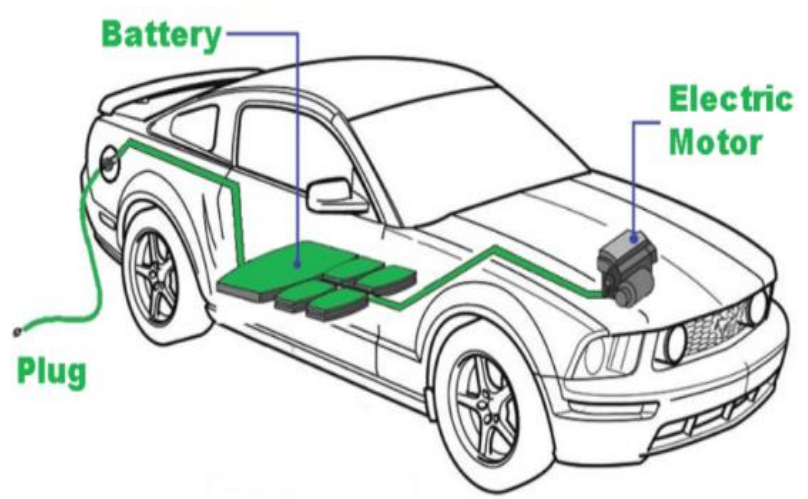

Fig 1.1

The core component in EV is Battery, which determines the Vehicle capability, so to improve the battery performance, much more research had done[4].Now-a-days, as a worldwide there is a huge demand of electric vehicles for their advantages and capabilities in the market. The origin of electric vehicle type is started from simple plug-in electric vehicle charging methods, which are good for safety where the problems are exposed plugs and damaged cables. There are four kinds of power conditioning units(PCUs) coupled to the battery, high-voltage dc-dc converters (HDCs), propulsion inverters, on-board chargers(OBCs) for high-voltage batteries (the propulsion battery), and lowvoltage dc-dc converters (LDCs) for auxiliary batteries in between the range 12-24 V. The normal way of approaching the EV PCUS is to use the housing and the cooling system[5]. By combining the reactor with a lower case and incorporating connectors, the number of components was decreased and the power efficiency of the Toyota Prius III was increased.

In this paper a battery charging system is analyzed which integrates a Non-Isolated On-Board Charger. A NonIsolated $\mathrm{DC} / \mathrm{DC}$ Converter is designed to improve the efficiency of an Electric Vehicle. A Cascaded buck-boost converter is partitioned with a capacitor i.e., before the capacitor in the converter boost operation and after the capacitor in the converter is buck operation is done and a bidirectional PWM converter is used for rectification and an inverter operation is performed during reverse feedback[6]. The output voltage obtained after both the operations (boost and buck) is given to the battery or load. This operation is done with PI controller and without PI controller in this paper. By using PI controller, a sinusoidal current waveform is generated by creating two bands to the reference current waveform with the help of hysteresis PWM technique, which results in higher efficiency[7]. 


\section{Design and Analysis of Higher Efficiency Non isolated DC-DC Converter for Electric Vehicles}

\section{PROPOSED CONVERTER}

\section{Topology 1: (Without PI controller)}

In this circuit cascading concept is used. In base paper a 3stage cascaded buck boost converter with 9 switches is used.

But giving pulses to those switches becomes complex. So instead of using rectifier alone, a bidirectional pwm converter is used and a cascaded buck-boost converter with the help of a partitioned capacitor is used.

The bidirectional converter acts as a rectifier and the output of the rectifier is given to the cascaded converter i.e., for the boost converter initially and the voltage gets boosted till this stage, later the capacitor acts as a partition or a separator between two legs of switches and the boosted voltage will be across capacitor, that capacitor acts as a source to buck Converter the desired Output voltage is supplied to battery with fundamental frequency.

\section{Topology 2: (With PI controller)}

In this circuit a universal bridge and a cascaded buck-boost converter is used. A three-phase source is given to threephase voltage and current measurement and is connected to $\mathrm{RL}$ branch. The obtained voltage is given to universal bridge. Pulses to the MOSFET is given through gate signal. Controlling of pulses is required for this circuit so a source rectifier subsystem is designed. It is necessary to transform from three-phase to two-phase axes, a transformation block is used and the two phase voltages are given to a PI controller. As we required higher efficiency, reactive power should be zero and there are two modes in this circuit, forward mode and reverse mode. In two modes for individual pulses controlling source rectifier subsystem is created. During rectification, gain to the current control is gives as unity, whereas in inverter mode gain is taken as -1 . After controlling of pulses the two-phase parameters are converted into three-phase parameters and is given to gate signal.

In this circuit, a bidirectional converter and a cascaded buck-boost converter is used. The bidirectional converter acts as a rectifier and the output voltage is given to the boost converter and the voltage is boosted till this stage, later the capacitor acts as a partition between two legs of switches and the boosted voltage will be across the capacitor, the capacitor acts as a source to the buck converter and the desired output voltage is supplied for battery to charge.

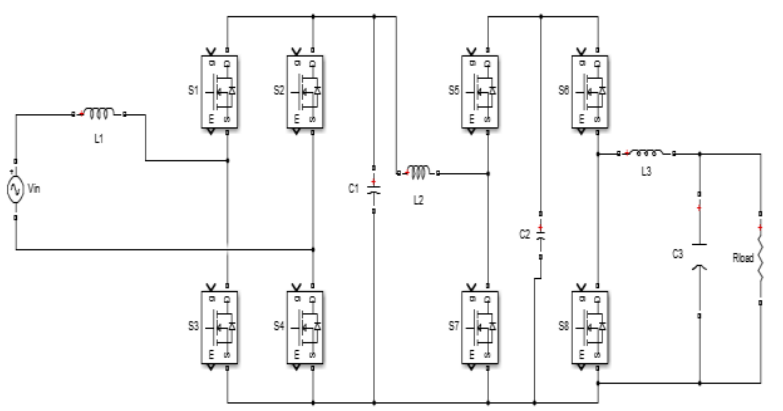

Fig: 2.1 Without PI control

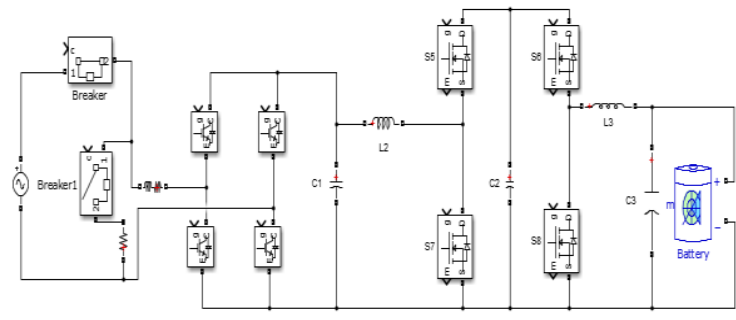

Fig:2.2 With PI controller

III.SIMULATION RESULTS:

\begin{tabular}{|c|c|c|}
\hline S.No & Specification & Rating \\
\hline 1 & Input Voltage & 100 Volts \\
\hline 2 & Voltage across C1 & 216 Volts \\
\hline 3 & Voltage across C2 & 700 Volts \\
\hline 4 & Voltage across C3 & 100 Volts \\
\hline 5 & $\begin{array}{c}\text { Nominal Voltage of } \\
\text { the induction machine }\end{array}$ & 300 Volts \\
\hline
\end{tabular}

Without PI controller:

\section{Supply voltage for DC/DC converter:}

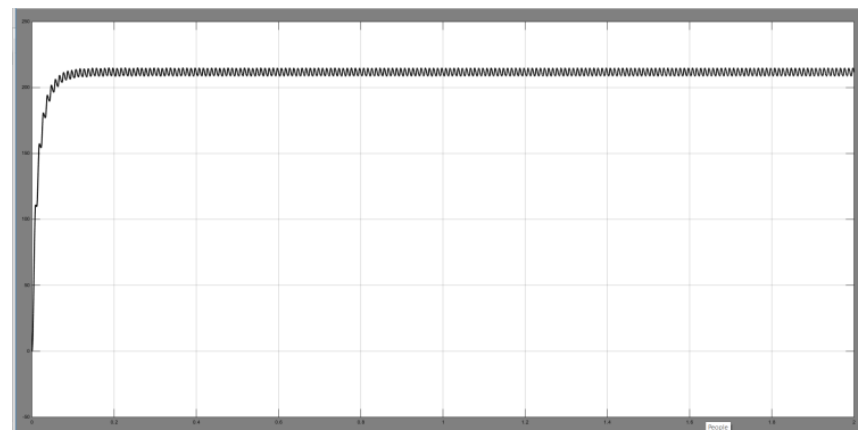

Fig 3.1- voltage across capacitor1

Source voltage $=216 \mathrm{~V}$ then Voltage across capacitor $1 \mathrm{Vc} 1=(0.9 * \mathrm{Vin})=(0.9 * 240)=216 \mathrm{~V}$

Voltage across C2(Boost Operation):

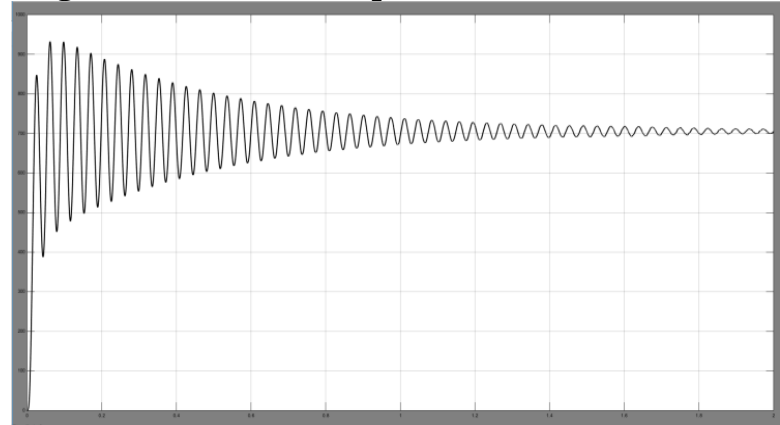

Fig 3.2- Voltage across the capacitor2

Duty ratio is taken as $70 \%$ depending on the input and output voltage Vc2 $=(\mathrm{Vc} 1 /(1-\mathrm{D}))=210 / 0.3=700 \mathrm{~V}$ 


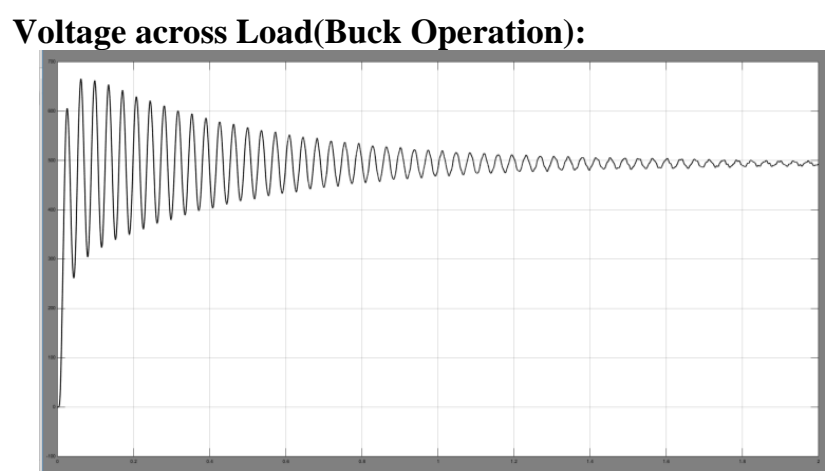

Fig 3.3-The above result shows the voltage across load after buck operation

Vload $=($ Vc $2 * D)=(700 * 0.7)=490 \mathrm{~V}$

With PI controller results:

\section{Charging mode:}

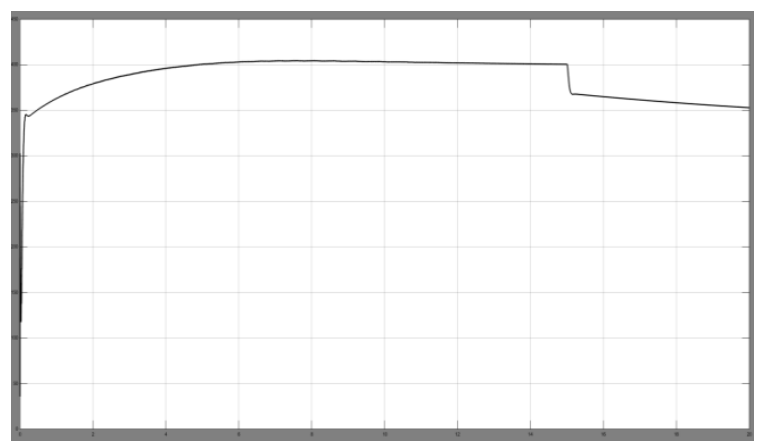

Fig:3.4 voltage across battery

Up to step signal comes to 15 , the bidirectional converter acts as a rectifier and the battery gets charged on the otherside i.e., after 15, the bidirectional converter acts as an inverter and the battery acts as a supply for the another load. Here load is considered as resistor.

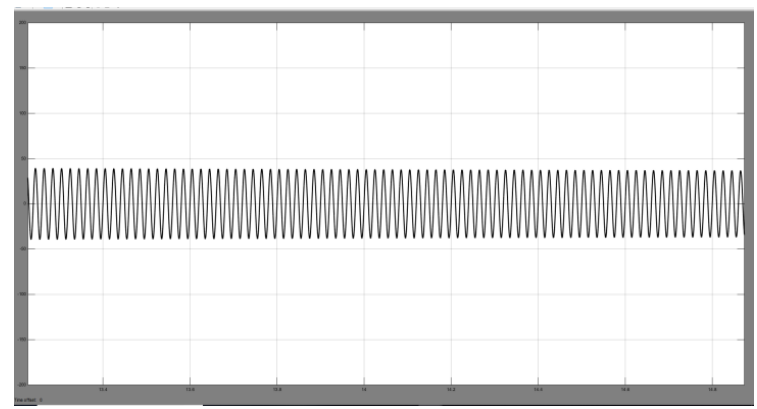

Fig: 3.5- current reference waveform

A current waveform is generated by using a PI controller and voltage from utility is taken along with the required voltage. These voltages are compared and multiplied.

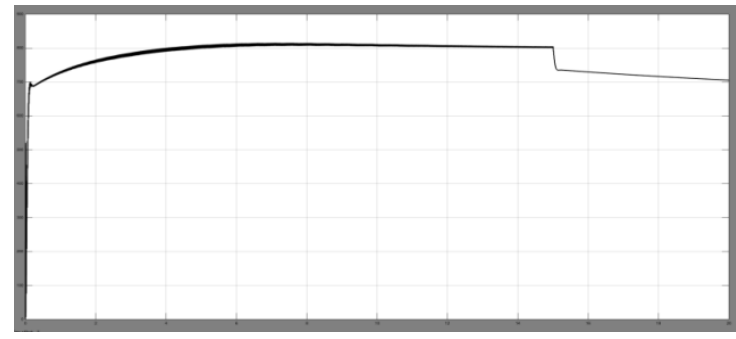

Fig:3.6-Voltage across the capacitor $\mathrm{C} 2$
In charging mode, the voltage across C2 is 700 volts and that voltage acts like a dc source to the buck converter which is at the load side.

Is\&Iref

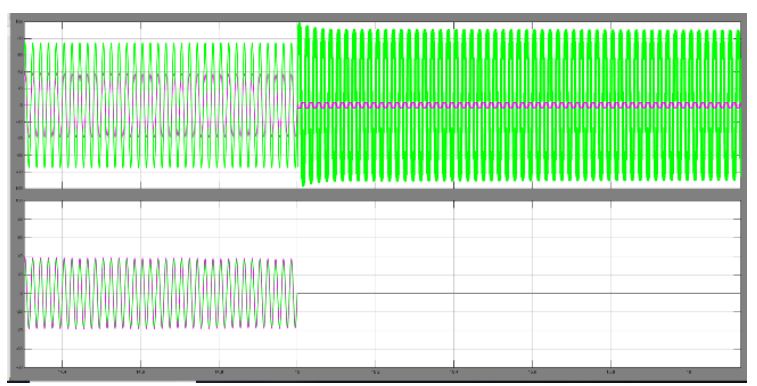

Fig:3.7- Complete operation of charging and discharging modes.

First half of the graph indicates charging i.e., till 15 and from 15 it goes into discharging mode. Analysis of both voltage and current is shown in the above graph.

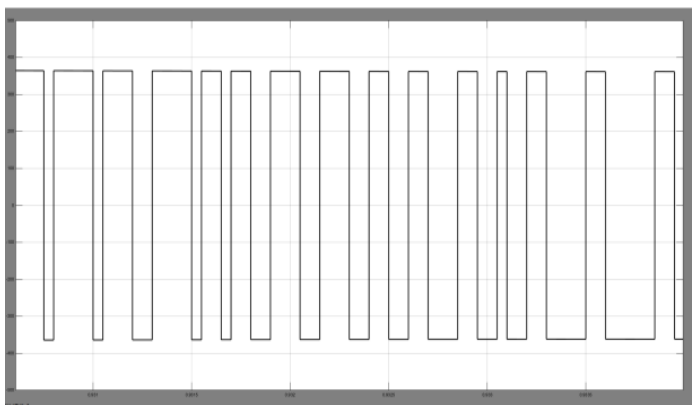

Fig: 3.8-Voltage from the utility

Voltage of 400 volts given to the bidirectional converter from the utility.

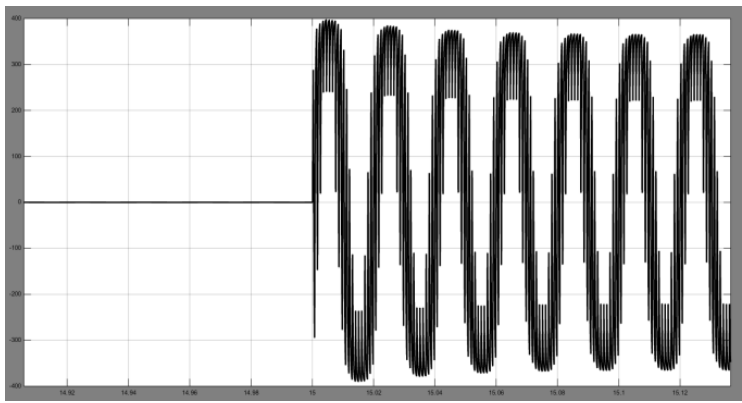

Fig:3.9- voltage during discharging mode

Till the step signal reaches to 15 , it will be charging mode. From 15 it goes into discharging mode and the power is fed back to the load here resistor acts as a load. This indicates the availability of voltage in discharging mode also. Hence bidirectional converter acts as an inverter in discharging mode of operation. 


\section{Design and Analysis of Higher Efficiency Non isolated DC-DC Converter for Electric Vehicles}

\section{CONCLUSION:}

A Bi-directional converter is designed for onboard charging of $480 \mathrm{~V}$ battery and power supply to drive system for an EV. Higher efficiency is achieved in charging mode owing to PWM control of bi-directional converter also a 2 stage cascaded dc/dc converter is implemented to further enhance the efficiency. the proposed system is tested under charging and discharging modes. and simulation results are presented up to validate the efficiency and bidirectional power conversion of the system.

\section{REFERENCES:}

1. P. Crist, "Electric Vehicles Revisited Costs, Subsidies and Prospects," Int. Trans. Forum, Paris, Tech. Rep., 2012.[Online]. Available: http://www.internationaltransportforum.org/jtrc/DiscussionPapers/ DP201203.pdf

2. S. Nozawa , T. Maekawa, E. Yagi, Y. Terao, and H. Kohno, "Development of new power control unit for compact-class vehicle," in Proc. Int. Symp. Power Semicond.Devices IC's, 2010, pp. 43-45.

3. S. H. Kim and K. F. Soon, "Multifunctional onboard battery charger for plug-in electric vehicles," IEEE Trans. Ind. Electron, vol. 62, no. 6, pp. 3460-3472, Jun. 2015.

4. Y.S.Kim, C.Y.Oh, W.Y.Sung, B.K. Lee, and G.C. Park, "Optimal design and control of OBC-LDC integrated power unit for electric vehicles," in Proc. IEEE Appl. Power Electron. Conf. Expo., Fort Worth, TX, USA, 2014, pp. 3192-3198.

5. D. Ouwerkerk, T. Han, and J. Preston, "Efficiency improvement using ahybridpowermodulein6.6kWnon-isolatedon-vehiclecharger,"inProc. IEEE Veh. Power Propul. Conf., Seoul, Korea, 2012, pp. 284-288.

6. C. Y. Oh, D. H. Kim, D. G. Woo, W. Y. Sung, Y. S. Kim, and B. K Lee, "A high-efficient non isolated single-stage on-board battery charger for ev,'IEEETrans.PowerElectron.,vol.28,no.12,pp.57465757, Dec. 2013.

7. M. Yilmaz and P. T. Krein, "Review of battery charger topologies, charging power levels, and infrastructure for plug-in electric and hybrid vehicles," IEEE Trans. Power Electron., vol. 28, no. 5, pp. 2151-2169, May 2013.

\section{AUTHORS PROFILE}

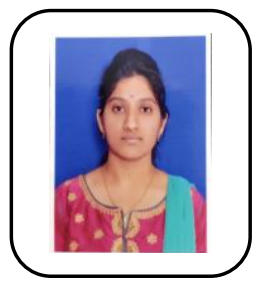

K. Keerthi born in Andhra Pradesh, India. She is pursuing her Bachelor's degree in electrical and electronics engineering from KLEF, Vaddeswaram, Guntur her research interests include electrical drives, power electronics, electric machines, renewable-energy systems, and electrical hybrid vehicles.

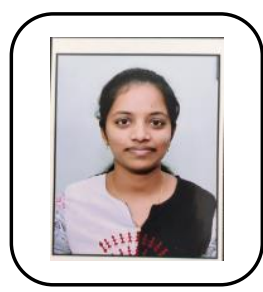

Y. Bhavya Sree born in Andhra Pradesh, India. She is pursuing her Bachelor's degree in electrical and electronics engineering from KLEF, Vaddeswaram, and Guntur. Her research interests include electrical drives, power electronics, electric machines, renewable-energy systems, and electrical hybrid vehicles. 